\title{
Arterial tortuosity syndrome in two Italian paediatric patients Marco Ritelli1 ${ }^{1}$, Bruno Drera ${ }^{1}$, Mariano Vicchio ${ }^{2}$, Giovanni Puppini³, Paolo Biban ${ }^{4}$, Mara Pilati ${ }^{5}$, Maria Antonia Prioli ${ }^{5}$, Sergio Barlati ${ }^{1}$ and Marina Colombi*1
}

\begin{abstract}
Address: ${ }^{1}$ Division of Biology and Genetics, Department of Biomedical Sciences and Biotechnology, Medical Faculty, University of Brescia, Brescia, Italy, ${ }^{2}$ Department of Cardio-Thoracic and Respiratory Sciences, Second University of Naples, Naples, Italy, ${ }^{3}$ Department of Radiology, Ospedale Civile Maggiore, Verona, Italy, ${ }^{4}$ Department of Pediatry, Ospedale Civile Maggiore, Verona, Italy and ${ }^{5}$ Department of Cardiology, Ospedale Civile Maggiore, Verona, Italy

Email: Marco Ritelli - ritelli@med.unibs.it; Bruno Drera - brunodrera@hotmail.com; Mariano Vicchio - marianovicchio@libero.it; Giovanni Puppini - giovanni.puppini@azosp.vr.it; Paolo Biban - paolo.biban@azosp.vr.it; Mara Pilati - marapilati@yahoo.it; Maria Antonia Prioli - maprioli@yahoo.it; Sergio Barlati - barlati@med.unibs.it; Marina Colombi* - colombi@med.unibs.it

* Corresponding author
\end{abstract}

Published: 25 September 2009

Orphanet Journal of Rare Diseases 2009, 4:20 doi:10.1186/1750-1172-4-20

Received: 5 June 2009

Accepted: 25 September 2009

This article is available from: http://www.ojrd.com/content/4/I/20

(C) 2009 Ritelli et al; licensee BioMed Central Ltd.

This is an Open Access article distributed under the terms of the Creative Commons Attribution License (http://creativecommons.org/licenses/by/2.0), which permits unrestricted use, distribution, and reproduction in any medium, provided the original work is properly cited.

\begin{abstract}
Background: Arterial tortuosity syndrome (ATS) (OMIM \#208050) is a rare autosomal recessive connective tissue disorder characterized by tortuosity and elongation of the large and mediumsized arteries, propensity to aneurysms formation, vascular dissection, and pulmonary arteries stenosis. ATS is caused by mutations in SLC2A10 gene, encoding for the facilitative glucose transporter 10 (GLUTI0). So far, 17 SLC2A 10 mutations have been reported in 32 families, two of which were Italian with a total of five patients. Here we present the clinical and molecular characterization of two novel Italian paediatric ATS patients.

Methods: The exons and intronic flanking regions of SLC2A 10 gene were amplified and direct sequencing was performed.

Results: In both patients, the involvement of major- and medium-sized arteries was characteristic; the nonvascular connective tissue manifestations were mild and not pathognomic of the disorder. Both patients, born from non-consanguineous parents, were heterozygous for two different SLC2A10 mutations, three of which were recurrent and one was novel (p.Arg23ITrp). This mutation is localized at the endofacial loop between the transmembrane domains 6 and 7 of GLUTIO.

Conclusion: Two novel ATS patients were characterized at clinical and molecular level. Overall, four ATS unrelated families are known in Italy so far. Though ATS clinical delineation improved in the last years, further works in the comprehension of disease presentation and complications onset, particularly in paediatric age, and on ATS molecular basis are needed to add new insights for diagnosis and prevention strategies for related complications.
\end{abstract}




\section{Background}

Arterial tortuosity syndrome (ATS) (OMIM \#208050) is an extremely rare autosomal recessive disorder characterized by tortuosity and elongation of the large and medium-sized arteries, propensity to aneurysms formation, vascular dissection, and pulmonary arteries stenosis. Other typical manifestations are dysmorphic features, hyperextensible skin, cutis laxa, herniae, skeletal abnormalities, joints hypermobility, and congenital contractures [1-4]. ATS is due to mutations in SLC2A10 gene, located on chromosome 20q13.1 and encoding for the 541 amino acid facilitative glucose transporter 10 (GLUT10), consisting in 12 transmembrane hydrophobic segments connected by 5 intracellular and 6 extracellular loops $[5,6]$. So far, 17 SLC2A10 mutations have been reported in 32 ATS families $[3-5,7,8]$. In this work we report the clinical findings and the molecular characterization of two Italian paediatric ATS patients.

\section{Case presentation}

Patient 1, an eight-months-old male baby, is the secondborn from non-consanguineous unaffected parents. He was born by cesarean section for malposition at the $36^{\text {th }}$ week of gestation after a pregnancy complicated by oligoidramnios. At birth, his weight was $2.680 \mathrm{~g}$ and Apgar index of 7 and 8 at 1 and 5 minutes, respectively. Because progressive signs of respiratory distress (i.e., tachypnea and $\mathrm{SatO}_{2}$ of 83\%) were noted soon after birth and given the presence of crackles at lung auscultation, antibiotic therapy and continuous positive airway pressure were started. Subsequently, the patient required synchronized intermittent mandatory ventilation with a $\mathrm{FiO}_{2}$ of about 45\%-50\% and was extubated after 8 days. Chest radiography, cranial and abdominal ultrasounds were normal. Cardiac echography showed a normal heart anatomy, but the presence of pulmonary hypertension signs and marked tortuosity of aortic arch. Magnetic Resonance Angiography (MRA) was needed (Figure 1,i). So far, staturo-ponderal growth is normal and, except facial dysmorphisms (Figure 1,ii), no cutaneous or skeletal involvement is noted. At six months the patient underwent to hernioplasty for bilateral congenital scrotalinguinal hernia without post-surgery complications. At 7 month the patient was hospitalized for bronchiolitis and respiratory instability.

Patient 2, a five-years-old child, is the first of two sons of healthy non-consanguineous parents of South Italy origins. He came to medical attention, without a previous significant clinical history, at four years, for sudden dyspnoea and asthenia during a usual activity. Echocardiography excluded heart disease and showed pulmonary hypertension; angiography disclosed severe stenoses, elongation, and tortuosity of pulmonary arteries branches, aortic arch, sovraortic trunks, and iliac arteries.
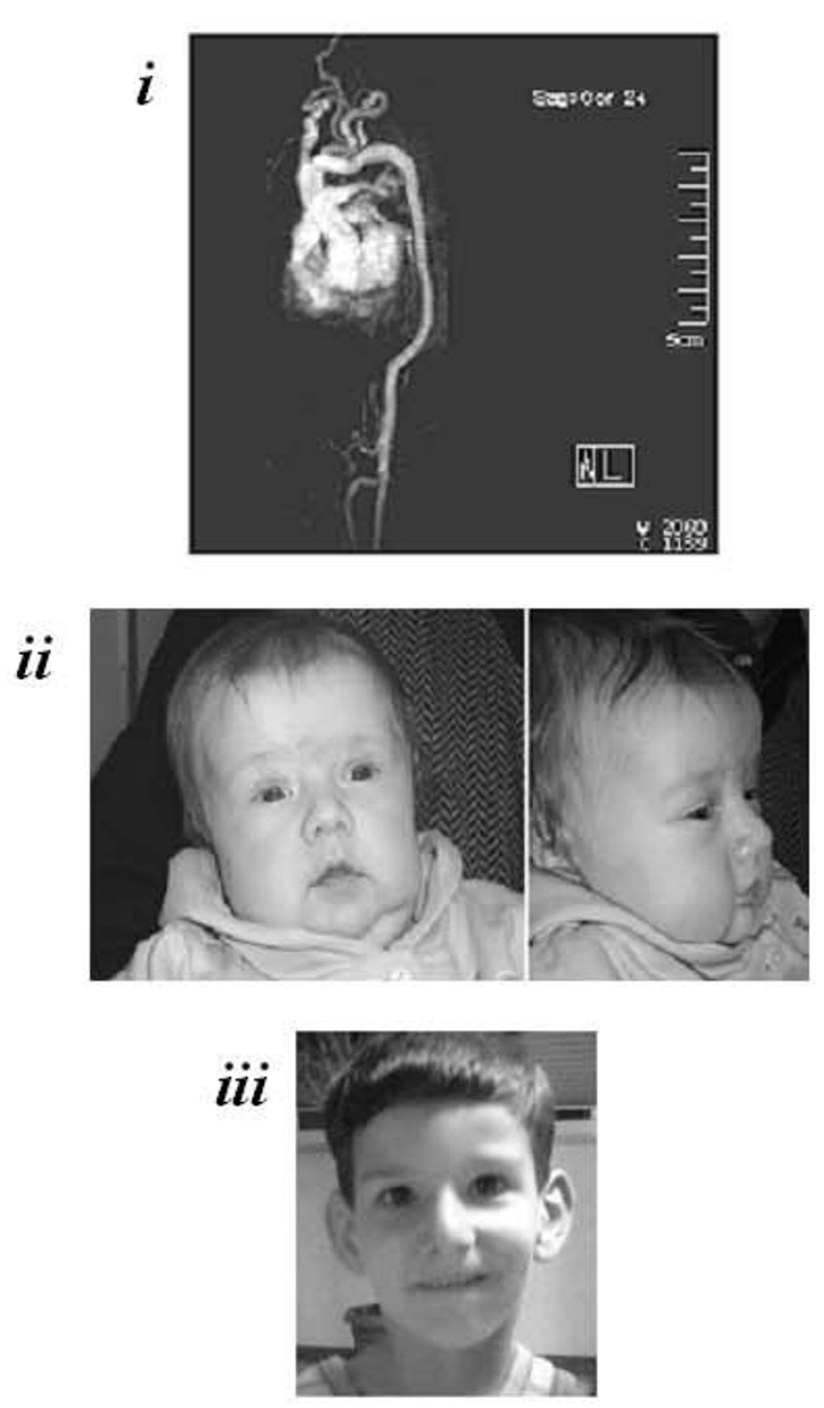

\section{Figure I}

Radiographic and facial features of the two Patients. i) MRA of Patient I showed tortuosity and kinking of aortic arch, mild hypoplasia of descending and abdominal aorta, tortuosity of all the sovraortic trunks with kinking of left common carotid and left subclavian arteries, ectasia of the innominate artery origin, and bilateral reduction of peripheral pulmonary branches. ii) Patient I showed elongated face, micrognathia, mild blepharophimosis, downslanting palpebral fissures, beaked nose, high-arched palate. iii) Patient 2 showed elongated face, low-set and anteverted ears, downslanting palpebral fissures, high nasal bridge.

Pulmonary hypertension treatment was carried out as previously reported [10]. Patient's extravascular findings were: facial features (Figure 1, iii), high-arched palate, scoliosis, pectus excavatum, and joints hypermobility. No cutaneous, ocular, or tegument involvement was observed. 
On the basis of the patients' phenotype SLC2A10 gene analysis was performed by exons amplification and direct sequencing, after written informed consent from patients parents. In Patient 1 genotyping disclosed the maternal c. $685 \mathrm{C}>\mathrm{T}$ transition and the paternal c.756C $>\mathrm{A}$ transversion, leading to p.Arg229X and the p.Cys252X nonsense mutations, respectively (Figure 2A). Both nucleotide substitutions were previously reported in homozygosity: the c. $685 \mathrm{C}>\mathrm{T}$ in a Belgian family [4], and the c.756C $>\mathrm{A}$ in a Kurdish patient [3]. In Patient 2 the maternal c.1334delG microdeletion, leading to the p.G445fsX484 recurrent mutation and the novel c.691C>T transition were disclosed (Figure 2B). The c.691C>T transition, detected in heterozygosity in the father and in the unaffected younger brother of the patient, affected the first position of the codon replacing a hydrophilic arginine residue with the hydrophobic tryptophan residue (p.Arg231Trp). The p.Arg231 was previously found substituted by a Gln residue, as the consequence of the c.692G>A transition, in three Spanish affected siblings, in compound heterozygosity with the c.1334delG mutation, like in our patient [4]. Nonsense and frameshift mutations, leading to a premature termination codon, could lead to nonsense mediated mRNA decay and allele loss-of-function [5]. On the other hand, missense mutations localized at an endofacial loop of GLUT10, like the p.Arg231Trp, should exert interference on the conformational changes of the protein necessary for the sugars transport $[5,7]$.

\section{Conclusion}

Two novel ATS patients were characterized at clinical and molecular level. Overall, four ATS unrelated families are known in Italy so far $[[1,6,7,9]$, this work]. Of the 17 SLC2A10 mutations so far identified, 9 were missense, 4 nonsense and 4 small out-of-frame deletions leading to premature termination codons. The c.1334delG and the c. 1309G $>$ A mutations are recurrent, as well as the c.243C>G mutation found in Qatari [11] and Middle Eastern families $[4,5,8]$. The mutations here identified underline the recurrence of known SLC2A10 mutations among ATS patients, suggesting that these mutations arose more than one time, or likely should be referred to a founder effect, as shown for the c.1334delG deletion, already found in ATS patients from European countries and showing identical haplotype $[4,5]$. Among these, of note, both Italian families were from South Italy [[5], this work].

On the basis of previous observations and on the reports of clinical findings of patients carrying the same mutations of ours, no genotype-phenotype correlation can be drawn. Indeed, neither the type nor the position of mutations correlates with specific manifestations, or with type and onset of complications. In the patients here reported, the involvement of major- and medium-sized arteries was characteristic, though the extravascular manifestations were mild and not pathognomic for the disorder. Both patients were suspected as affected with ATS following the onset of acute respiratory symptoms, caused by hypertension of pulmonary branches, in the immediate perinatal period (Patient 1), and in the second infancy, in an apparent otherwise healthy child without a significant clinical history addressing a precocious diagnosis (Patient 2). Both conditions were life-threatening events needing
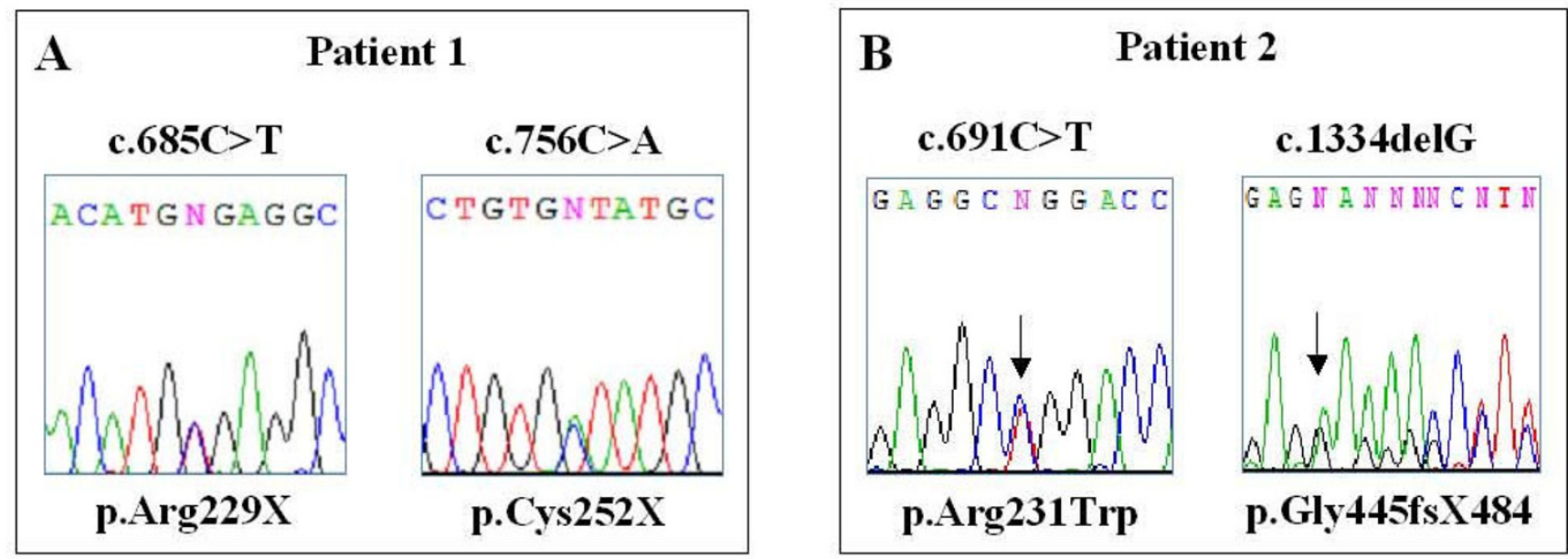

\section{Figure 2}

Molecular characterization of the patients by SLC2A 10 sequencing on genomic DNA, obtained from whole peripheral blood of the patients, after written informed consent given by the parents. A) Patient I genotyping: the c.685C $>\mathrm{T}$ transition and the c.756C $>\mathrm{A}$ transversion, both in exon 2 and leading to p.Arg229X and the p.Cys $252 \mathrm{X}$ nonsense mutations, respectively B) Chromatograms of mutations identified in Patient 2: the recurrent c. I334delG microdeletion in exon 3 and the novel c.69lC>T transition in exon 2. 
emergency treatments and investigations. Though ATS prognosis has been recently downsized and thought to be less severe than initially reported (i.e., a mortality rate up to $40 \%$ before the age of 5 years), death in young age was referred to respiratory insufficiency, ventricular hypertrophy resulting in global heart failure, myocarditis, and ischemic events leading to organs infarction [2,4]. Among these causes, pulmonary infections, like the reported bronchiolitis in Patient 1, playing as trigger events of respiratory distress and acute cardiac failure, are thought to be serious events in young ATS patients [2,12-14].

Our results indicate that patients exhibiting arterial tortuosity with mild or without extravascular connective tissue manifestations should be screened for SLC2A10 gene mutations.

Further works in the comprehension of the natural history and on the molecular basis of ATS are needed to add new insights for diagnosis and prevention strategies for related complications.

\section{Consent}

Written informed consent was obtained from patients parents for publication of this case report and accompanying images.

\section{List of abbreviations used}

ATS: arterial tortuosity syndrome; SLC2A10: solute carrier family 2, member 10; GLUT10: facilitative glucose transporter 10; MRA: Magnetic Resonance Angiography.

\section{Competing interests}

The authors declare that they have no competing interests.

\section{Authors' contributions}

MC conceived the study. BD and MR carried out the molecular analysis, researched the literature reviewed and prepared the manuscript. $\mathrm{BD}, \mathrm{MV}, \mathrm{GP}, \mathrm{PB}, \mathrm{MP}, \mathrm{MAP}$ diagnosed the patients. SB contributed to the discussion section. MC edited and coordinated the manuscript. All authors read and approved the final manuscript.

\section{Acknowledgements}

The authors wish to thank the families involved in this study for their collaboration. This research was supported by Fondazione Cariplo "ZebraGene" Grant 2007 and Ministero dell'Istruzione dell'Universitàe della Ricerca, Fondo per gli investimenti della Ricerca di Base 2008.

\section{References}

I. Gardella R, Zoppi N, Assanelli D, Muiesan ML, Barlati S, Colombi M: Exclusion of candidate genes in a family with arterial tortuosity syndrome. Am J Med Genet A 2004, I 26:22I-228.

2. Wessels MW, Catsman-Berrevoets CE, Mancini GM, Breuning MH, Hoogeboom JJ, Stroink H, Frohn-Mulder I, Coucke PJ, Paepe AD, Niermeijer MF, Willems P]: Three new families with arterial tortuosity syndrome. Am J Med Genet A 2004, I 3 I:134-143.
3. Zaidi SH, Meyer S, Peltekova VD, Lindinger A, Teebi AS, Faiyaz-UIHaque M: A novel non-sense mutation in the SLC2AIO gene of an arterial tortuosity syndrome patient of Kurdish origin. Eur J Pediatr 2009, 168:867-870.

4. Callewaert BL, Willaert A, Kerstjens-Frederikse WS, De Backer J, Devriendt K, Albrecht B, Ramos-Arroyo MA, Doco-Fenzy M, Hennekam RC, Pyeritz RE, Krogmann ON, Gillessen-kaesbach G, Wakeling EL, Nik-zainal S, Francannet C, Mauran P, Booth C, Barrow M, Dekens R, Loeys BL, Coucke PJ, De Paepe AM: Arterial tortuosity syndrome: clinical and molecular findings in 12 newly identified families. Hum Mutat 2008, 29:150-I58.

5. Coucke P, Willaert A, Wessels MW, Callewaert B, Zoppi N, De Backer J, Fox JE, Mancini GM, Kambouris M, Gardella R, Facchetti F, Willems PJ, Forsyth R, Dietz HC, Barlati S, Colombi M, Loeys B, De Paepe $A$ : Mutations in the facilitative glucose transporter GLUTI 0 alter angiogenesis and cause arterial tortuosity syndrome. Nat Genet 2006, 38:452-457.

6. Coucke PJ, Wessels M, Van Acker P, Gardella R, Barlati S, Willems PJ, Colombi M, De Paepe A: Homozygosity mapping of a gene for arterial tortuosity syndrome to chromosome $20 \mathrm{ql}$. J Med Genet 2003, 40:747-75I.

7. Drera B, Guala A, Zoppi N, Franceschini P, Barlati S, Colombi M: Two novel SLC2A I0/GLUTIO mutations in a patient with arterial tortuosity syndrome. Am J Med Genet A 2007, 143:216-218.

8. Faiyaz-Ul-Haque M, Zaidi SH, Al-Sanna N, Alswaid A, Momenah T, Kaya N, Al-Dayel F, Bouhoaigah I, Saliem M, Tsui LC, Teebi AS: A novel missense and a recurrent mutation in SLC2A 10 gene of patients affected with arterial tortuosity syndrome. Atherosclerosis 2009, 203:466-47I.

9. Franceschini P, Guala A, Licata D, Di Cara G, Franceschini D: Arterial tortuosity syndrome. Am J Med Genet A 2000, 9 I:| |4I- I 43.

10. Vicchio M, Santoro G, Carrozza M, Caianiello G: Hybrid approach in a case of arterial tortuosity syndrome. Interact Cardiovasc Thorac Surg 2008, 7:736-737.

II. Faiyaz-UI-Haque M, Zaidi SH, Wahab AA, Eltohami E, Al-Mureikhi MS, Al-Thani G, Peltekova VD, Tsui LC, Teebi AS: Identification of a p.Ser8 I Arg encoding mutation in SLC2A I 0 gene of arterial tortuosity syndrome patients from 10 Qatari families. Clin Genet 2008, 74:189-193.

12. Adès LC, Knight WB, Byard RW, Bateman JF, Esquivel JA, Mee RB, Haan EA, Milewicz DM: Clinicopathologic findings in congenital aneurysms of the great vessels. Am J Med Genet A 1996 , 66:289-299.

13. Beuren AJ, Hort W, Kalbfleisch H, Müller H, Stoermer J: Dysplasia of the systemic and pulmonary arterial system with tortuosity and lengthening of the arteries. A new entity, diagnosed during life, and leading to coronary death in early childhood. Circulation 1969, 39:109-115.

14. Pletcher BA, Fox JE, Boxer RA, Singh S, Blumenthal D, Cohen T, Brunson S, Tafreshi P, Kahn E: Four sibs with arterial tortuosity: description and review of the literature. Am J Med Genet $A$ 1996, 66:121-128.

Publish with Bio Med Central and every scientist can read your work free of charge

"BioMed Central will be the most significant development for disseminating the results of biomedical research in our lifetime. "

Sir Paul Nurse, Cancer Research UK

Your research papers will be:

- available free of charge to the entire biomedical community

- peer reviewed and published immediately upon acceptance

- cited in PubMed and archived on PubMed Central

- yours - you keep the copyright 